profession shortly is proof of the failure of our professional regulators to act in our best interests and prepare us for the future and so is the CQC furore.

The ramifications are significant and create yet another damaging blow to the low morale of the dental team. Keith is right - on the present evidence, the GDC is cash-greedy, outdated and patronising.

N. J. Knott

By email

DOI: 10.1038/sj.bdj.2011.7

\section{DUTY OF CARE}

Sir, I read with interest your recent editorial (BDJ 2010; 209: 421) regarding ethics in today's dentistry. It was followed by a letter from A. Sorrell (BDJ 2010; 209: 423) raising a number of points on corporate bodies and their apparent failings to provide a duty of care to some patients. There has been frequent discussion concerning dentists who may be under pressure regarding UDAs having to pick and choose the treatments received by patients in high need. One must remember our duty of care is to our patients, not our employers.

In addition to the points raised by A. Sorrell, I would like to draw attention to the misuse of the referral system which I have observed whilst working in the hospital environment. It sees high numbers of routine restorative treatments which may not be financially beneficial to the dentist finding their way on to hospital waiting lists. Whilst teaching hospitals are thankful for some routine treatments for undergraduate students to put into practice skills learnt on phantom heads, patients can spend months waiting for treatment, often in pain and end up needing treatment which is more extensive than when the referral was originally made.

Many referrals extended to oral surgery where patients were referred for routine extractions due to 'dental anxiety'. This anxiety was often not known to the patients concerned who were more than happy to have extractions under local anaesthesia. I am unsure whether the reason for these referrals is due to the UDA structure or the recognised lack of oral surgery experience as an undergraduate for recent graduates.
In a manner as to not discourage referrals, repeat referrals for routine treatment from the same dentists/practice may warrant further investigation. These dentists may appreciate support from postgraduate centres. Appropriate practical courses may improve the dentists' confidence in providing certain treatments for their patients.

Whilst the option remains for hospitals to write back to dentists enquiring as to why certain treatment cannot be carried out by the referring dentist, this places the patient at a further disadvantage of waiting even longer for treatment. Hence patients getting treated using hospital resources. One would hope the ongoing review and future proposals for the UDA system may improve this situation.

Finally, I would like to acknowledge that not all questionable referrals I have experienced were from corporate bodies, but a significant majority were from that source.

S. Roddis

By email

DOI: 10.1038/sj.bdj.2011.8

\section{FOUR HANDED WISDOM}

Sir, I write in regard to the letter Musculoskeletal pain (BDJ 2010; 209: 425). When I was a dental student in the late sixties, early seventies I remember having one session on 'four handed dentistry' with Ellis Paul who was a part-time lecturer at Liverpool Dental School.

The most important aspect I remember was obtaining the correct seating position and height of the operating stool for oneself before approaching the dental chair to set its height and tilt and then positioning the headrest.

For the 36 years I was in practice I rarely suffered from musculoskeletal problems, in fact if I came in to work on a Monday morning suffering from the effects of gardening over the weekend, by mid-morning the stiff back would have eased considerably. It is easy to maintain these positions with presets on the dental chair and of course, if nobody else uses one's surgery!

The few times that I did have trouble was usually after my clinical assistant session at a local hospital in a surgery which was used by many other dentists. By the end of the following week any adjustments I had made would have long been changed!

Whilst I did not take my four handed skills to the heights of Mr Paul's ability I am grateful for his words of wisdom all those years ago.

K. Maunder

Spondon

DOI: 10.1038/sj.bdj.2011.9

\section{UNDERMINING CONSENT}

Sir, I am an orthodontist and have for many years practised a form of nonsurgical therapy called orthotropics, the name of which may well be familiar to your readers. I have found this able to avoid orthognathic surgery for many patients who had previously been told that surgery was the only option. In my estimation these results were often as good as, if not better than 'conventional' surgery.

As a result of a recent General Dental Council hearing, in which I was involved, the Council has decided that it is not necessary for orthodontists, even when proposing major orthognathic surgery, to include the possibility of being treated by orthotropics. I believe that this undermines the basis of informed consent as it should be the patient who decides which treatment they prefer and they can only do that if they are aware of alternatives. I will be pleased to hear, through your columns, from colleagues as to whether they think this is a retrograde step.

J. Mew By email

DOI: 10.1038/sj.bdj.2011.10

\section{APPROPRIATE DISPENSING}

Sir, I have enjoyed the series of cover images in Volume 209 of the journal, where abstract art depicts one of the GDC specialties. The cover on Issue 6, however, representing paediatric dentistry, raises an issue which is often overlooked when depicting images of a toothbrush and toothpaste. The graphic shows two brushes, overloaded with copious amounts of paste, a not uncommon finding in illustrations and photographs used in health education material aimed at young children and their parents. Since the early $1990 s^{1}$ it has been agreed that the amount of toothpaste used by children should be restricted 
to a smear (under three years) or peasize amount (3-6-years-old) - a message endorsed on tubes of fluoride containing toothpaste sold in the UK and recognised in national ${ }^{2,3}$ and international ${ }^{4}$ clinical guidelines.

Whilst recognising the freedom that abstract art enjoys and the professional nature of the intended audience on this occasion, your cover provides an opportune reminder to those involved in producing health education material, of the importance of reinforcing in pictures and graphics, the message about appropriate dispensing of toothpaste for young children.

\section{G. Chestnutt} Cardiff

1. Pang D T, Vann W F. The use of fluoride-containing toothpastes in young children: The scientific evidence for recommending a small quantity. Pediatr Dent 1992; 14: 384-387.

2. Scottish Intercollegiate Guidelines Network. No 83. Prevention and management of dental decay in the pre-school child. A national Clinical Guideline. Edinburgh: Scottish Intercollegiate Guidelines Network, 2005

3. Department of Health. Delivering better oral health - an evidence-based -toolkit for prevention. 26 September 2007.

4. American Academy of Pediatric Dentistry. Guideline on fluoride therapy. Reference Manual: Clinical Guidelines. 2008 www.aapd.org/media policies_guidelines/g_fluoridetherapy.pdf

DOI: 10.1038/sj.bdj.2011.11

\section{KEEP PUBLISHING!}

Sir, I read with interest the letter describing an oral and maxillofacial surgery team's child protection referral for a three-month-old baby who presented with an isolated intraoral injury and was subsequently found to have multiple skeletal injuries indicative of severe physical abuse (Non-accidental injury; $B D J$ 2010; 209: 424). It sounds as if the timely actions of this team saved the little boy's life. The importance of making a timely referral when observing any oral injury in a non-mobile baby is sadly highlighted by three cases reported $^{1}$ where this did not occur, and all three infants re-presented with severe abusive head trauma.

I write to draw attention to the value of publishing such reports, particularly if your correspondents were to consider taking this further and writing the case up in detail for publication in a peer-reviewed journal. At the present time there is a paucity of large well designed comparative studies of abusive and non-abusive intraoral injuries $^{2,3}$ so this is a field in which a carefully-written individual case report can still make an important contribution to our knowledge.

Recent systematic reviews, particularly the work of the Welsh Child Protection Review Group, ${ }^{4}$ have clarified the evidence base for diagnosis and decision making in cases of child maltreatment. However, a systematic review of the literature related to intraoral injuries ${ }^{2}$ found that potentially relevant studies had to be excluded because of insufficient detail on the certainty of diagnosis that abuse had taken place: whether it was merely 'suspected' (ranked as level 5) or confirmed at case conference, civil or criminal court proceedings or admitted by the perpetrator (level 1).

If authors, assisted by journal referees, were to ensure that this information is included alongside a detailed description of the injuries present, occult and overt, and the mechanism of injury, where known, such case reports will be of greatest value for future reviews.

\section{J. Harris} Sheffield

1. Thackeray J D. Frena tears and abusive head injury: a cautionary tale. Pediatr Emerg Care 2007; 23: 735-737.

2. Maguire $S A$, Hunter $B$, Hunter L et al. Diagnosing abuse: a systematic review of torn frenum and other intra-oral injuries. Arch Dis Child 2007; 92: 1113-1117.

3. National Collaborating Centre for Women's and Children's Health. National Institute for Health and Clinical Excellence clinical guideline 89: When to suspect child maltreatment: full guideline. 2009. http://guidance.nice.org.uk/CG89

4. Welsh Child Protection Systematic Review Group. Core info. http://www.core-info.cardiff.ac.uk

DOI: 10.1038/sj.bdj.2011.12

\section{DENTAL DOCTOR}

Sir, I wonder if I could add a comment to the letter Incorrect and misleading (BDJ 2010; 209: 424).

The letter got me thinking back to my school days, and German lessons. Entering 'zahnartz' into Google translate gives 'dentist'. Splitting the word into its component parts, zahn gives dental and artz gives doctor. Hence the German for dentist is dental doctor.

DOI: 10.1038/sj.bdj.2011.13 